\section{OC-036 PERIPHERAL OEDEMA IS ASSOCIATED WITH POOR OUTCOMES FOLLOWING EMERGENCY ABDOMINAL SURGERY}

doi:10.1136/gutjnl-2012-302514a.36

${ }^{1} \mathrm{P}$ G Vaughan-Shaw, ${ }^{*} \mathrm{~S}$ Jones, ${ }^{2} \mathrm{~J}$ A Saunders, ${ }^{2} \mathrm{M}$ A Stroud, ${ }^{2} \mathrm{~T}$ R Smith, ${ }^{1} \mathrm{~A}$ T King. ${ }^{1}$ Department of Lower GI Surgery, University Hospital Southampton NHS Foundation Trust, Southampton, UK; ${ }^{2}$ Southampton NIHR Nutrition, Diet and Lifestyle BRU, University Hospital Southampton NHS Foundation Trust, Southampton, UK

Introduction Peripheral oedema is frequently observed in critically ill patients following surgery and is commonly attributed to poor nutritional status and associated with worse outcomes. This study assesses the prevalence of generalised oedema following emergency abdominal surgery and the value of early post-operative oedema measurement in predicting clinical outcome.

Methods A prospective cohort study of patients undergoing emergency abdominal surgery at a university surgical unit over a 2 -month period was undertaken. Nutritional status data were collected and oedema measured in the early post-operative period. Clinical outcome data were collected until discharge and at subsequent outpatient consultations.

Results 55 patients were included, median age 66. Post-operative complications included ileus $(n=9)$, sepsis $(n=6)$ and death $(n=10)$. Post-operative oedema was present in 19 patients (35\%) and associated with prolonged peri-operative fasting ( 4 vs 1 days, $p=0.009$ ) but not BMI (24 vs $27 \mathrm{~kg} / \mathrm{m}^{2}, \mathrm{p}=0.16$ ) or pre-admission weight loss $(5 \%$ vs $3 \%, p=0.9)$. Oedema was associated with prolonged hospitalisation ( 24 vs 10 days, $\mathrm{p}=0.0004$ ), complications and/or death (68\% vs $31 \%, p=0.007)$ and a trend towards increased artificial nutritional support ( $42 \%$ vs $22 \%, p=0.07)$. Presence of oedema independently predicted death $(\mathrm{p}=0.016)$, median follow-up 155.5 days.

Conclusion Generalised oedema is common after emergency abdominal surgery but not predicted by commonly used markers of nutritional status such as BMI or recent weight loss in. Increased peri-operative fasting and subsequent intravenous fluid administration may be a significant contributor to post-operative oedema. Measurement of post-operative oedema may offer utility in identifying those at risk of poor clinical outcome or those requiring artificial nutritional support.

Competing interests None declared.

\section{OC-037 VITAMIN D DEFICIENCY IS COMMON IN INTESTINAL FAILURE PATIENTS}

doi:10.1136/gutjnl-2012-302514a.37

A Culkin, ${ }^{*}$ B Rye, C Hanson. St Mark's Hospital, Harrow, UK

Introduction Vitamin D is essential due to its role in bone health and its immunomodulatory propeties. ${ }^{1}$ Patients with intestinal failure (IF) are at risk of Vitamin D deficiency due to inadequate absorption and lack of exposure to UVB light. Deficiency has been demonstrated in IF patients dependent on home parenteral nutrition. ${ }^{2}$ We aimed to determine the prevalence of vitamin $\mathrm{D}$ deficiency in hospital patients with IF and the efficacy of subsequent prescribed treatment.

Methods All patients admitted to St Mark's Hospital with IF over a 12-month period were included and data on demographics, serum total vitamin $\mathrm{D}$ concentration, IF aetiology and vitamin $\mathrm{D}$ supplementation prescribed were obtained. If deficiency was identified $(\leq 50 \mathrm{nmol} / \mathrm{l})$ the efficacy of treatment provided was assessed. Descriptive analysis and t-tests were performed.

Results Eighty-four patients were included in the study (42 female, mean age $53 \pm 15$ years, $92 \%$ Caucasian). The aetiology of IF included short bowel $(n=30)$, fistula $(n=34)$, small bowel obstruction $(n=13)$, malabsorption $(n=5)$ and others $(n=2)$. Vitamin $D$ was measured in $76 \%(n=64)$ of patients and $75 \%(n=48)$ were deficient (mean $41 \pm 25 \mathrm{nmol} / 1$, range 9-126). Vitamin D concentrations were lower in men $(33.4 \pm 15.3 \mathrm{nmol} / \mathrm{l})$ compared to women $(49.5 \pm 29.5 \mathrm{nmol} / \mathrm{l}) \quad(\mathrm{p}=0.009)$. No association was demonstrated with age, aetiology of IF, or ethnicity. There was a trend towards reduced Vitamin D and increasing BMI ( $\left.p=0.187, \mathrm{r}^{2}=0.028\right)$. No seasonal variation was demonstrated between summer (June-November, $42.8 \pm 26.5 \mathrm{nmol} / \mathrm{l}$ ) and winter (December-May, $39.3 \pm 21.6 \mathrm{nmol} / \mathrm{l}) \quad(\mathrm{p}=0.57)$. Only $26 \%(\mathrm{n}=22)$ of patients had repeat vitamin $\mathrm{D}$ concentrations before discharge. There was a significant increase in vitamin $D$ concentrations from $35 \pm 22 \mathrm{nmol} / \mathrm{l}$ to $44.8 \pm 14.3 \mathrm{nmol} / \mathrm{l}, \quad(\mathrm{p}=0.03)$. Twenty-nine patients received intramuscular Vitamin D at a dose of 300000 IU. In these patients there was an increase in concentration before $(28.4 \pm 13.6 \mathrm{nmol} / \mathrm{l})$ and after $(42.8 \pm 12.7 \mathrm{nmol} / \mathrm{l})$. Due to the small numbers of patients it was not possible to determine the efficacy of the different vitamin $\mathrm{D}$ preparations or the effect of the multivitamin preparation used in parenteral nutrition (Cernevit ${ }^{\circledR}$ ) on serum concentrations.

Conclusion Vitamin D deficiency is common and occurs in threequarters of IF patients. Male gender was associated with lower concentrations. Robust policies need to be in place for the identification of vitamin $\mathrm{D}$ deficiency including the supplementation and monitoring of vitamin $\mathrm{D}$ deficiency in patients with IF to ensure adequate serum concentrations are achieved.

Competing interests None declared.

\section{REFERENCES}

1. Michal L, Melamed. 25-Hydroxyvitamin D levels and the risk of mortality in the general population Arch Intern Med 2008;168:1629.

2. Tee CT, et al. Hypovitaminosis $D$ in patients on long-term parenteral nutrition. Proc Nut Soc 2010;69:E554.

\section{OC-038 HEALTHCARE USE ACCORDING TO BODY MASS INDEX (BMI) CATEGORY IN INDIVIDUALS REGISTERED TO GP PRACTICES}

doi:10.1136/gutjnl-2012-302514a.38

K E Ashman, ${ }^{*}$ A L Cawood, R J Stratton. Medical Affairs, Nutricia, Trowbridge, UK

Introduction Previous studies have assessed the relationship between body mass index (BMI) and healthcare use in primary care settings but have been limited to individuals with pre-defined diseases or those with a recorded diagnosis of malnutrition. ${ }^{1-3}$ This study using data from The Health Improvement Network (THIN) database (UK) aimed to examine GP-related healthcare use and hospital admissions according to two BMI categories (underweight and normal weight) across all individuals registered to GP practice.

Methods Two cohorts of individuals registered with GPs were randomly selected from the THIN database (Cohort 1 BMI $\leq 19.9 \mathrm{~kg} / \mathrm{m}^{2} \mathrm{n} 2632$, Cohort 2 BMI 20.0 to $\leq 24.9 \mathrm{~kg} / \mathrm{m}^{2} \mathrm{n} 2632$ ). Cohorts were matched for age (52 y (22.4)), gender ( $81 \%$ female) and GP practice. Individuals were included if they had at least two BMIs recorded from May 2010 to May 2011 and were registered for at least 12 months. Individuals were excluded if they; were living in institutions, had conditions affecting weight for example, oedema, had a BMI $<13.0 \mathrm{~kg} / \mathrm{m}^{2}$, or receiving palliative/end of life care. GPrelated healthcare use (practice visits, home visits, out of hours visits, telephone consultations) and hospital admissions over 1 year were retrieved using read codes and locate flags; and a simple cost analysis was undertaken using unit costs. ${ }^{4}$

Results A significantly greater proportion of individuals with a BMI $\leq 19.9 \mathrm{~kg} / \mathrm{m}^{2}$ had at least one; home, out of hours visit or telephone consultation with the GP practice (Abstract OC-038 table 1), and 
had significantly more practice visits than individuals with a BMI 20.0 to $\leq 24.9 \mathrm{~kg} / \mathrm{m}^{2}$ (8.5 vs 8.3 visits respectively $p=0.022$ Mann-Whitney U). Similar results were seen for hospital admissions, with a significantly greater proportion of individuals with a BMI $\leq 19.9 \mathrm{~kg} / \mathrm{m}^{2}$ being admitted to hospital (Abstract OC-038 table 1). Compared to individuals with a BMI 20.0 to $\leq 24.9 \mathrm{~kg} / \mathrm{m}^{2}$, mean GP contact costs per person per year were increased by $£ 29.54$ and admissions by $£ 34.62$ per year. ${ }^{5}$

\section{Abstract 0C-038 Table 1}

\begin{tabular}{lllll}
\hline & & $\begin{array}{l}\text { 1. BMI } \leq \mathbf{1 9 . 9} \\
\mathbf{k g} / \mathbf{m}^{\mathbf{2}} \text { (n2632) }\end{array}$ & $\begin{array}{l}\text { 2. BMI 20 } \\
\text { to } \leq 24.9 ~ \mathbf{~ k} / \mathbf{m}^{2} \\
\text { (n2632) }\end{array}$ & p Value \\
\hline Home visits & $\% \geq 1$ & 11.4 & 7.4 & $0.000^{*}$ \\
Out of hours visits & $\% \geq 1$ & 4.8 & 3.4 & $0.006^{*}$ \\
Telephone consultations & $\% \geq 1$ & 50.6 & 46.2 & $0.001^{*}$ \\
Hospital admissions & $\% \geq 1$ & 4.6 & 3.6 & $0.026^{*}$ \\
\hline (Significance: $\left.{ }^{*} \chi^{2}\right)$. & & & &
\end{tabular}

Conclusion This study using data from THIN shows that individuals registered with their GP, with a low BMI $\left(\leq 19.9 \mathrm{~kg} / \mathrm{m}^{2}\right)$ use significantly more healthcare resources than those with a normal BMI $\left(20.0\right.$ to $\left.\leq 24.9 \mathrm{~kg} / \mathrm{m}^{2}\right)$. The contribution of disease types and severity, social and nutrition-related factors needs to be further evaluated.

Competing interests $\mathrm{K}$ Ashman Employee of: Nutricia, A Cawood Employee of: Nutricia, R Stratton Employee of: Nutricia.

\section{REFERENCES}

Martyn CN, et al. Clin Nutr 1998;17:119-23.

2. Edington J, et al. Proc Nutr Soc 1999;58:655-61.

3. Guest JF, et al. Clin Nutr 2011;30:422-9.

4. Curtis L. Unit cost of health and social care. 2010

\section{OC-039 ORAL NUTRITIONAL SUPPLEMENTS ARE COST EFFECTIVE IN IMPROVING QUALITY ADJUSTED LIFE YEARS IN MALNOURISHED CARE HOME RESIDENTS}

doi:10.1136/gutjnl-2012-302514a.39

E L Parsons, * R J Stratton, J M Jackson, M Elia. Institute of Human Nutrition, University of Southampton, Southampton, UK

Introduction Malnutrition has a detrimental effect on quality of life (QOL) but the extent to which nutrition support can improve QOL in a cost effective manner is unclear. This study aimed to examine whether oral nutritional supplements are cost effective in improving quality adjusted life years (OALY's) (an index of quality and quantity of life) in malnourished care home residents.

Methods A randomised controlled trial (RCT) of 104 malnourished residents (medium + high risk according to Malnutrition Universal Screening Tool ("MUST")) (mean age $88.3 \pm 7.7 \mathrm{y}, 86 \%$ female) in residential and nursing homes in Hampshire received either oral nutritional supplements (ONS) with guidance on how to use them (Nutricia range; mean intake $333 \pm 237 \mathrm{kcal} / \mathrm{d} ; \mathrm{n}=53$ ) or written and verbal dietary advice (DA) for 12 weeks. OALY's were calculated using quality of life, measured with EuroQol Time Trade Off (EO5D TTO) and information on mortality. Expenditure on healthcare use (healthcare professional visits and hospital admissions (for the 3 months prior to and during the RCT)) and the interventions were calculated using unit costs. ${ }^{1} 2$ The expenditure and OALY's were used to establish the Incremental Cost Effectiveness Ratio (ICER). Results OALY TTO was significantly higher in the ONS group than the DA group $(0.14 \pm 0.04$ vs $0.12 \pm 0.03, p=0.023$, total $n=70)$. Total expenditure was greater in the ONS group than the DA group
(ONS: $£ 375.70 \pm 213.78, \mathrm{DA}: £ 173.85 \pm 240.15, \mathrm{p}<0.0001)$ due to the cost of the intervention (ONS: $£ 173.71 \pm 126.06$, DA: $£ 39.75 \pm 32.25$, $\mathrm{p}<0.0001)$. Healthcare use costs were not significantly different between groups (ONS: £153.62 \pm 208.44 , DA: $£ 127.27 \pm 250.03$, $\mathrm{p}=0.639)$. The mean ICER (cost/OALY TTO) was $£ 10698(95 \% \mathrm{CI}$ $£ 3793$ to $£ 76932$ ), which is well below the typically considered threshold of $£ 25000 /$ OALY indicative of cost effectiveness.

Conclusion This RCT indicates that compared to simple dietary advice, oral nutritional supplements are cost effective in improving the quality adjusted life years of malnourished care home residents.

Competing interests None declared.

\section{REFERENCES}

1. Curtis L. Unit Costs of Health and Social Care. University of Kent, 2009.

2. British National Formulary. 42 edn. 2006.

\section{OC-040 REGULAR NUTRITIONAL BLOOD TEST MONITORING IN CHILDREN ON HOME ENTERAL TUBE FEEDING - IS THIS NECESSARY?}

doi:10.1136/gutjnl-2012-302514a.40

${ }^{1} \mathrm{Y}$ Lim, ${ }^{*} \mathrm{C}$ Paxton, ${ }^{2} \mathrm{D}$ Wilson. ${ }^{1}$ Paediatric Gastroenterology and Nutrition, NHS Lothian; ${ }^{2}$ Child Health and Life, University of Edinburgh, Edinburgh, UK

Introduction The use of home enteral tube feeding (HETF) in children with chronic illness is increasing. 6-monthly nutritional blood test monitoring (NBTM) while on HETF is recommended by BAPEN for adults; there is minimal evidence to inform guidelines regarding the biochemical monitoring of children on long-term HETF.

Aim To provide evidence for or against the practice of 6-monthly NBTM in children receiving HETF.

Methods We performed a retrospective review of all children age $<18$ years, who were started on HETF from 01 January 2005 to 30 June 2010 by the nutrition support team (NST) in the Royal Hospital for Sick Children, Edinburgh. Patients who received $<2$ months of HETF, or failed to receive more than one set of NBTM within the 1st year of starting HETF were excluded. Comparison of baseline NBTM results with results at 6-12 months after the start of HETF were made. Our NBTM profile includes full blood count, renal profile, bone profile, liver function tests, folate, ferritin, vitamin $\mathrm{B}_{12}$, fat-soluble vitamins and trace elements (Se, $\mathrm{Cu}, \mathrm{Zn}$ ).

Results 42 children were included in the study; none developed refeeding syndrome. 37 (88\%) had NBTM performed within 6 months of commencing HETF, 19 (45\%) at 6 months after commencing HETF, and $21(50 \%)$ at 1 year after commencing HETF. Significant abnormal parameters identified prior to commencing HETF included low Hb levels (32\%), low ferritin levels (31\%) and low folate levels (25\%). Small groups of between $8 \%$ and $10 \%$ had low levels of trace elements ( $\mathrm{Se}$ and $\mathrm{Cu}$ ) and vitamin $\mathrm{D}$ levels. At 6 months and 1 year after start of HETF, there was a small increase of children with low Hb levels (40\%) but an improvement in those with low ferritin (14\%) and low folate levels (6\%). $4 \%$ of the study had low vitamin $\mathrm{D}$, and/or trace element ( $\mathrm{Zn}, \mathrm{Cu}, \mathrm{Se}$ ) levels. There were no toxic levels of vitamins or trace elements within 12 months of start of HETF. Trend comparison was performed in 25 children who had NBTM both before and within a year of commencing HETF. None of the children developed toxic levels of trace elements, one child developed high trace element levels (Se) and another continued to have high Se levels after starting HETF. None of the children developed toxic or high levels of fat soluble vitamins. There were no worryingly low micronutrient levels in any of the 25 children after the start of HETF. 